\title{
Use of electronic health records for early detection of high-cost, low back pain patients
}

\author{
Daniel D Maeng PhD ${ }^{1}$, Walter F Stewart PhD MPH${ }^{2}$, Xiaowei Yan $\mathrm{PhD}^{2}$, Joseph A Boscarino PhD MPH${ }^{1}$, \\ Jack Mardekian $\mathrm{PhD}^{3}$, James Harnett PharmD MS ${ }^{3}$, Michael $\mathrm{R}$ Von Korff ScD 4
}

\begin{abstract}
DD Maeng, WF Stewart, X Yan, et al. Use of electronic health records for early detection of high-cost, low back pain patients. Pain Res Manag 2015;20(5):234-240.
\end{abstract}

BACKGROUND: Low back pain (LBP) is a debilitating condition that is complex to manage. One reason is that clinicians lack means to identify early on patients who are likely to become high care utilizers. OBJECTIVE: To explore the feasibility of developing a 'dynamic' predictive model using electronic health record data to identify costly LBP patients within the first year after their initial LBP encounter with a primary care provider. Dynamic, in this context, indicates a process in which the decision on how to manage patients is dependent on whether they are at their first, second or third LBP visit with the provider.

METHODS: A series of logistic regression models was developed to predict who will be a high-cost patient (defined as top 30\% of the cost distribution) at each of the first three LBP visits.

RESULTS: The c-statistics of the three logistic regression models corresponding to each of the first three visits were $0.683,0.795$ and 0.741 , respectively. The overall sensitivity of the model was $42 \%$, the specificity was $86 \%$ and the positive predictive value was $48 \%$. Men were more likely to become expensive than women, while patients who had workers' compensation as their primary payer type had higher use of prescription opioid drugs or were smokers before the first LBP visit were also more likely to become expensive.

CONCLUSION: The results suggest that it is feasible to develop a dynamic, primary care provider visit-based predictive model for LBP care based on longitudinal data obtained via electronic health records.

Key Words: Cost of care; Electronic health records; Low back pain; Predictive model

$\mathbf{B}$ ack pain is the most common pain problem in the general popula$\mathrm{B}_{\text {tion }}(1,2)$ and is a common reason for seeking care (3). Individuals vary substantially in the frequency of pain episodes and flare-ups, the duration of episodes, and the extent to which a pain problem progresses to a severe disorder (eg, more frequent episodes or flare-ups or more disabling pain) (4). Often, pain episodes and flare-ups naturally remit and recur in an episodic manner. With appropriate care, most patients improve as they learn to effectively manage through painful episodes, minimizing impact on their functioning (5). However, for a substantial minority of patients, the pain episodes become more frequent, more intense or increase in duration, and eventually progress to a more severe disease stage with consequences for treatment response, mental health, physical functioning and utilization of health care (6). In some cases, the pain problem may be resolved or mitigated through surgery or other interventions.

\section{Le recours aux dossiers de santé électroniques pour le dépistage rapide des patients atteints de douleurs lombaires qui coûtent cher}

HISTORIQUE : Les douleurs lombaires (DL) sont débilitantes et difficiles
à traiter, en partie parce que les cliniciens ne peuvent pas déceler rapidement
les patients susceptibles de devenir de grands utilisateurs de soins.
OBJECTIF : Explorer la faisabilité d'élaborer un modèle prédicteur
« dynamique » à l'aide des données des dossiers de santé électroniques
pour déterminer les patients atteints de DL qui coûteront cher, et ce, dans
l'année suivant leur premier rendez-vous avec un dispensateur de soins de
première ligne en raison de DL. Ainsi, dans un processus dynamique, la
décision quant au mode de prise en charge des patients repose sur le fait que
le patient en est à son premier, deuxième ou troisième rendez-vous en rai-
son de DL. MÉTHODOLOGIE : Les chercheurs ont créé une série de modèles de régression logistique pour prédire qui sera un patient qui coûtera cher (défini comme les $30 \%$ supérieurs de la répartition des coûts) à chacun des trois premiers rendez-vous en raison de DL.

RÉSULTATS : La statistique $\mathrm{C}$ des trois modèles de régression logistique correspondant à chacun des trois rendez-vous s'élevait à 0,683, 0,795 et 0,741 , respectivement. La sensibilité globale du modèle était de $42 \%$, sa spécificité, de $86 \%$, et sa valeur prédictive positive, de $48 \%$. Les hommes étaient plus susceptibles de coûter plus cher que les femmes, tandis que les patients dont le principal type de rémunération provenait de l'indemnisation des accidentés du travail utilisaient davantage d'opioïdes sur ordonnance. Ceux qui fumaient avant leur premier rendez-vous en raison de DL risquaient également davantage de coûter plus cher.

CONCLUSION : Les résultats laissent croire à la faisabilité de créer un modèle dynamique prédicteur des rendez-vous avec des dispensateurs de soins de première ligne en raison de DL en fonction de données longitudinales tirées des dossiers de santé électroniques.

For many patients with low back pain (LBP), however, unnecessary use of health care is common (7-9). In this context, we characterize unnecessary use of care as 'avoidable care'. Simply stated, avoidable care encompasses any type of health care for which evidence indicates that it is not useful for LBP or does not improve patient outcomes, or for which there is no evidence of utility for a patient with LBP. Some examples of avoidable include duplicate high-end imaging (ie, computed tomography scans or magnetic resonance imaging) and multiple surgeries. Indeed, use of imaging, specialty care and surgery is common among patients with a LBP problem despite a lack of demonstrated effectiveness of such care in this population (10). In the present study, we aimed to provide a way to detect early those patients who may be subject to such avoidable care before they receive it.

The main goal of the present study was to explore the feasibility of using electronic health record (EHR) data collected in routine primary

\footnotetext{
${ }^{1}$ Geisinger Center for Health Research, Danville, Pennsylvania; ${ }^{2}$ Sutter Health, Walnut Creek, California; ${ }^{3}$ Pfizer Inc, New York, New York; ${ }^{4}$ Group Health Research Institute, Seattle, Washington, USA

Correspondence: Dr Daniel D Maeng, Geisinger Center for Health Research, 100 North Academy Avenue, MC 44-00, Danville, Pennsylvania 17822, USA. Telephone 570-214-1688, fax 570-214-5170, e-mail ddmaeng@geisinger.edu
} 
care provider (PCP) office visits to understand the relationship between the occurrence of LBP in primary care patients and variation in the pattern of utilization of care that follow an initial visit. More specifically, the present study sought to determine whether there are enough 'signals' within the routinely collected clinical and other administrative data within EHR to predict future utilization patterns of LBP patients. If true, this ability to do so is likely to open opportunities to provide point-of-care decision support to mitigate the future event (ie, reducing avoidable care). Note that the present study did not explicitly develop actual predictive models that can readily be implemented in physician practices; instead, the modelling approach presented explored the possibility of developing such models through future research.

The present study was reviewed by Geisinger Health System's (Pennsylvania, USA) Institutional Review Board and was determined that it met the requirements for an exempt status, because only deidentified patient-level data were collected and used. As of July 1, 2013, Geisinger Health System included 44 primary and 34 specialty care clinics and $>1000$ employed physicians serving approximately 2.4 million residents throughout 44 counties in Central Pennsylvania. Geisinger Health Plan (GHP), which is the financing arm of the Geisinger Health System, provides health insurance coverage to approximately $30 \%$ of Geisinger Health System's patient population. The present study utilized the mature EHR database of Geisinger Health System, which has been in place and fully functional across all its care sites since the 1990s.

The sample size for the present study was fixed by the duration of the observation window (January 1, 2007 to December 20, 2011). The LBP patient cohort included in the study was defined using Vogt's criteria for classifying LBP patients into four mutually exclusive subgroups (I, II, III and IV) (11). The incident cohort was defined as patients who did not have a LBP diagnosis for at least six months before the first LBP-related encounter or visit with a Geisinger provider. This incident cohort was further limited to individuals who had at least one year of follow-up after the first LBP visit, resulting in a final analytic sample of 37,800 unique patients.

Tables 1 and 2 summarize the demographic and baseline clinical characteristics as well as care utilization patterns among the low-versus high-cost LBP patients included in the cohort. Note that patient characteristics, such as age, sex, chronic conditions, smoking status and body mass index, are routinely collected data elements within the typical EHR. The frequency and interval of primary care visits can also be obtained readily from the EHR for those who are established patients in the PCP office. The cost of care information, however, is not routinely available in typical EHRs. For this particular information, the EHR data need to be linked to the PCP's billing information. Note that, in this context, the absolute dollar value associated with each encounter type is not as important as its relative value in relation to other encounter types - that is, because the cost estimates are used only to classify the patients in the sample into a binary category of high cost (defined, as discussed below, as $>70$ th percentile in the distribution of the cost estimates) versus low cost, what matters is that the cost estimates reflect the relative magnitude of the care 'intensity' associated with each encounter type as captured by the payment rate of the payer.

In the present study, we exploited the fact that approximately $30 \%$ of the LBP patient cohort in our data had health insurance coverage through GHP. Thus, the corresponding GHP claims data for this subcohort of the LBP patients were also obtained. Then we developed a cost imputation algorithm (described in the Appendix) based on the observed encounters-to-claims associations in that subcohort and imputed missing cost information to those patients who did not have GHP coverage (see the Appendix for the detailed description of this imputation algorithm). Applying this method to our EHR data, we obtained an average cost estimate of approximately US $\$ 2,600$ per patient per visit. As expected, the distribution of this estimated cost data was heavily skewed; the corresponding median was US\$310 with interquartile range of US\$167 to US\$591.
TABLE 1

Demographic and health profile of adult primary care patients with at least one incident low back pain (LBP) visit

\begin{tabular}{|c|c|c|}
\hline \multirow[b]{2}{*}{ Variable } & \multicolumn{2}{|c|}{ Cost profile } \\
\hline & $\begin{array}{l}\text { Low cost } \\
(n=26,457)\end{array}$ & $\begin{array}{l}\text { High cost }^{*} \\
(n=11,343)\end{array}$ \\
\hline$\overline{\text { Female sex }}{ }^{\dagger}$ & 62.86 & 58.12 \\
\hline \multicolumn{3}{|l|}{ Age, years ${ }^{\dagger}$} \\
\hline$<30$ & 12.24 & 9.2 \\
\hline $30-39$ & 15.57 & 13.91 \\
\hline $40-49$ & 21.05 & 21.14 \\
\hline $50-59$ & 20.62 & 22.08 \\
\hline$\geq 60$ & 30.53 & 33.67 \\
\hline \multicolumn{3}{|l|}{ Smoking status ${ }^{\dagger}$} \\
\hline Current smoking & 19.3 & 22.65 \\
\hline Quit & 20.59 & 22.21 \\
\hline Never & 37.88 & 32.58 \\
\hline Missing & 22.22 & 22.57 \\
\hline \multicolumn{3}{|l|}{ Body mass index $\geq 30 \mathrm{~kg} / \mathrm{m}^{2 \dagger}$} \\
\hline Yes & 45.12 & 48.14 \\
\hline Missing & 4.35 & 2.73 \\
\hline \multicolumn{3}{|l|}{ Chronic progressive diagnosis } \\
\hline Type II diabetes $^{\dagger}$ & 16.14 & 19.64 \\
\hline Hypertension $^{\dagger}$ & 41.89 & 47.39 \\
\hline Stroke/hemorrhage $^{\dagger}$ & 6.31 & 8.44 \\
\hline Coronary artery disease $^{\dagger}$ & 6.39 & 9.57 \\
\hline Heart failure ${ }^{\dagger}$ & 3.39 & 4.99 \\
\hline \multicolumn{3}{|l|}{ Chronic episodic diagnosis } \\
\hline Migraine $^{\dagger}$ & 23.93 & 25.82 \\
\hline Arthritis ${ }^{\dagger}$ & 31.53 & 39.63 \\
\hline Irritable bowel syndrome & 5.75 & 5.83 \\
\hline Gastroesophageal reflux disease $^{\dagger}$ & 32.03 & 34.5 \\
\hline Asthma & 14.03 & 14.71 \\
\hline Allergic rhinitis ${ }^{\dagger}$ & 26.06 & 24.01 \\
\hline \multicolumn{3}{|l|}{ Diagnosed depression severity ${ }^{\dagger}$} \\
\hline None & 68.63 & 61.61 \\
\hline Mild-moderate & 20.63 & 24.1 \\
\hline Severe & 10.74 & 14.28 \\
\hline Anxiety disorder diagnosis ${ }^{\dagger}$ & 11.91 & 13.77 \\
\hline Sleep disorder diagnosis ${ }^{\dagger}$ & 18.77 & 24.07 \\
\hline Fibromyalgia diagnosis ${ }^{\dagger}$ & 14.56 & 21.37 \\
\hline \multicolumn{3}{|c|}{ Charleston comorbidity index before LBP first encounter } \\
\hline Mean \pm SD & $0.56 \pm 1.07$ & $0.63 \pm 1.14$ \\
\hline Median & 0 & 0 \\
\hline Interquartile range & $0-1$ & $0-1$ \\
\hline
\end{tabular}

Data presented as \% unless otherwise specified (may not sum to $100 \%$ for each variable because only relevant data were included). *>US $\$ 1,176$ or 70 th percentile of the first year LBP cost; ${ }^{\dagger}$ Indicates statistical significance among groups. $\chi^{2}$ test is used for categorical variables, and Kruskal Wallis nonparametric test is used for continuous variables

\section{METHODS}

Figure 1 indicates that much of the activity associated with LBP care occurs during the first several visits in the first year after an initial LBP encounter. In fact, much of the diagnostic testing (ie, imaging and laboratory), which presumably determines the subsequent patterns of care, occurs during the first three visits. This implies that the types of care the patient receives in subsequent visits are critically dependent on how the patient was treated during the first three visits. Based on this insight, a visit-by-visit predictive modelling approach was developed that utilizes the signals and information available to the clinician at the time of each visit, as described below. 
TABLE 2

Utilization of care profile among adult primary care patients with at least one incident low back pain (LBP) visit according to cost profile

\begin{tabular}{|c|c|c|}
\hline \multirow[b]{2}{*}{ Variable } & \multicolumn{2}{|c|}{ Cost profile } \\
\hline & $\begin{array}{l}\text { Low cost } \\
(n=26,457)\end{array}$ & $\begin{array}{l}\text { High cost } \\
(n=11,343)\end{array}$ \\
\hline First LBP encounter with $\mathrm{PCP}^{*}$ & 75.28 & 64.18 \\
\hline \multicolumn{3}{|c|}{ Follow-up time (years) to first LBP encounter* } \\
\hline Mean \pm SD & $2.54 \pm 1.08$ & $2.59 \pm 1.07$ \\
\hline Median & 2.57 & 2.64 \\
\hline Interquartile range & $1.69-3.50$ & $1.67-3.45$ \\
\hline \multicolumn{3}{|c|}{$\begin{array}{l}\text { Total number of encounters in year before } \\
\text { first LBP encounter* }\end{array}$} \\
\hline $0-2$ & 0.18 & 0.23 \\
\hline $3-6$ & 15.62 & 16.57 \\
\hline $7-10$ & 27.95 & 25.21 \\
\hline $11-15$ & 19.84 & 18.23 \\
\hline$>15$ & 15.84 & 15.80 \\
\hline \multicolumn{3}{|c|}{$\begin{array}{l}\text { Total opioid prescriptions in the year before } \\
\text { the first LBP encounter* }\end{array}$} \\
\hline Nonuser & 93.61 & 89.85 \\
\hline 1 & 2.25 & 3.12 \\
\hline $2-4$ & 2.49 & 3.98 \\
\hline $5+$ & 1.66 & 3.05 \\
\hline \multicolumn{3}{|l|}{ LBP diagnosis group* } \\
\hline 1 & 72.47 & 43.71 \\
\hline II & 10.84 & 11.59 \\
\hline Illa & 1.18 & 0.90 \\
\hline IIllb & 11.78 & 38.48 \\
\hline IV & 0.95 & 2.39 \\
\hline Other & 2.78 & 2.93 \\
\hline \multicolumn{3}{|l|}{ Physician efficiency index* } \\
\hline Mean \pm SD & $1.3 \pm 1.47$ & $2.05 \pm 2.87$ \\
\hline Median & 0.82 & 1.0 \\
\hline Interquartile range & $0.60-1.36$ & $0.67-2.39$ \\
\hline \multicolumn{3}{|l|}{ Insurance information* } \\
\hline Commercial & 43.01 & 39.28 \\
\hline Medicaid & 7.60 & 10.80 \\
\hline Medicare & 23.77 & 26.61 \\
\hline Worker's company & 1.04 & 1.97 \\
\hline
\end{tabular}

Data presented as \%. *Indicates statistical significance among groups. MantelHaenszel $\chi^{2}$ test was used for categorical variables, and Kruskal-Wallis nonparametric test was used for continuous variables. PCP Primary care physician

Logistic regression models were used to predict who would become a high-cost patient after the first visit. High cost was defined as any patient who used care over the subsequent 12 months that was $\geq \mathrm{US} \$ 1,176$ or the 70 th percentile of the distribution. A one-year period versus a three- or five-year period was selected because one year is typically used by payers to assess patient costs. While results from models using a three- and five-year time frame are not shown, it turns out that the c-statistic is only slightly diminished even when using such extended time horizon. The c-statistic, or area under the receiver operator curve (AUC), was used to assess each model's ability to distinguish those with and without high costs. With AUC values ranging from 0 to 1, Hosmer and Lemeshow have suggested that a c-statistic or AUC value between 0.70 and 0.80 is acceptable, and a value $>0.80$ is excellent, with values $>0.90$ being rarely observed. As a benchmark, the c-statistic for a commonly used risk assessment tool, the Framingham Heart Study risk calculator (12), is 0.77 .

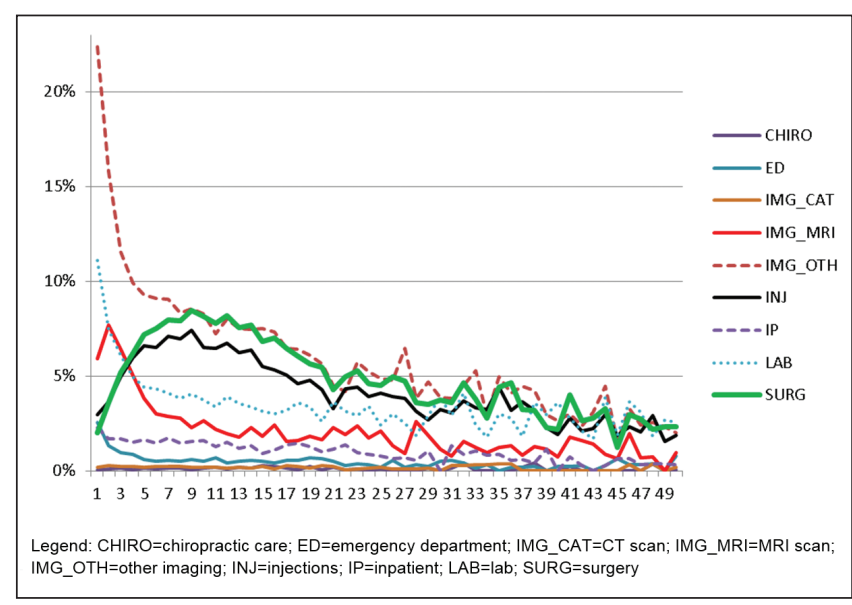

Figure 1) Utilization profile according to low back pain (LBP) visit in one year after initial LBP encounter

In addition, sensitivity, specificity and positive predictive values were assessed based on the estimated probability that each patient would be high cost in subsequent visits and selecting an arbitrary cutpoint for the probability (in this case $>0.4$ ) to determine true and false positives. That is, if a patient's probability is greater than the cut-point ( $>0.4)$ AND was high cost ( $>70$ th percentile), the patient was classified as a true positive - ie, the patient was correctly identified by the model to be a high-cost patient in a subsequent visit. Similarly, if the patient had a probability that was greater than the cut-point but was NOT high cost, the patient was classified as a false positive - ie, the patient was incorrectly identified as high cost even though they were not high cost in a subsequent visit. The same logic is applied to each of the first three visits to gradually identify true and false positives in each visit.

The key feature of this model is the ability to identify those patients who are likely to require greater management efforts with increasing precision in each subsequent visit. That is, during the first visit, some portion of the patients who make the initial LBP visit will be determined to be high cost (depending on the cut-point used). Those who are determined to be high cost will then be flagged for a follow-up intervention and be excluded from the model in the following visit. The second visit model then focuses on the remaining patients who were determined to be low cost in the second visit. The same process is then applied to the third visit. Because the model builds on what becomes known in the previous and current visits, its precision becomes greater in later iterations.

The sensitivity and specificity of this model is subject to two main parameters: definition of 'high cost' patients and the probability cutpoints. For instance, more conservative definitions of these parameters - eg, defining high cost to be 80th percentile as opposed to 70th percentile, and the probability cut-point of 0.6 as opposed to 0.4 - will lead to higher specificity but lower sensitivity.

Table 3 summarizes the predictor variables used to develop the model. The same set of predictors were used in all three of the models because there is no a priori guidance on which variable should be included or excluded from each model. As such, the objective is to find as many early signals - ie, signals that exist at or before the first LBP encounter - as possible that can readily be obtained from each patient's longitudinal EHR data and explore their predictive power.

One of the main predictors in the predictive model is physician efficiency index (PEI). This index represents the average cost of care across all other patients treated by the same provider during the given calendar year. The formula for calculating PEI is shown below:

$$
P \mathrm{II}_{\mathrm{ij}}=\left[\left(\sum_{\mathrm{i}=1}^{\mathrm{N}} \text { Cost }_{\mathrm{i}}\right)-\text { Cost }_{\mathrm{i}}\right] \div(\mathrm{N}-1)
$$


TABLE 3

\section{List of predictors and their descriptions}

\begin{tabular}{|c|c|c|}
\hline Predictor & Variable type & Description \\
\hline Age & Continuous & In years at the time of visit \\
\hline Diagnosis subgroup & Categorical & I (reference), II, III or IV \\
\hline \multirow[t]{4}{*}{ Age $\times$ subgroup } & Interaction & Age at subgroup II \\
\hline & Interaction & Age at subgroup III \\
\hline & Interaction & Age at subgroup IV \\
\hline & Interaction & Age at subgroup other \\
\hline Sex & Binary & Female versus male \\
\hline First LBP is PCP or not & Binary & Yes versus no \\
\hline Charlson score & Continuous & Comorbidity score \\
\hline Time interval & Continuous & $\begin{array}{l}\text { Number of months between } \\
\text { first and second LBP visit }\end{array}$ \\
\hline \multirow[t]{3}{*}{ Smoking } & Binary & Missing versus no \\
\hline & Binary & Quit versus no \\
\hline & Binary & Yes versus no \\
\hline \multirow[t]{2}{*}{ Alcohol } & Binary & Missing versus no \\
\hline & Binary & Yes versus no \\
\hline $\begin{array}{l}\text { Number of opioid } \\
\text { prescriptions before LBP }\end{array}$ & Count & $\begin{array}{l}\text { Number of opioid prescrip- } \\
\text { tions before first LBP visit }\end{array}$ \\
\hline First LBP visit is ED & Binary & Yes versus no \\
\hline CT order at first LBP & Binary & Yes versus no \\
\hline MRI order at first LBP & Binary & Yes versus no \\
\hline Other image at first LBP & Binary & Yes versus no \\
\hline Injection order at first LBP & Binary & Yes versus no \\
\hline Med order at first LBP & Binary & Yes versus no \\
\hline Lab order at first LBP & Binary & Yes versus no \\
\hline Number of visits before LBP & Count & $\begin{array}{l}\text { Number of visits for any } \\
\text { reason before first LBP visit }\end{array}$ \\
\hline \multirow[t]{4}{*}{ Depression } & Binary & Level 2 versus level 1 \\
\hline & Binary & Level 3 versus level 1 \\
\hline & Binary & Level 4 versus level 1 \\
\hline & Binary & Level 5 versus level 1 \\
\hline Allergic rhinitis & Binary & Yes versus no \\
\hline Arthritis & Binary & Yes versus no \\
\hline \multirow[t]{3}{*}{ Beta-blocker and HT } & Binary & $\begin{array}{l}\text { Beta-blocker order not for HT } \\
\text { versus no beta-blocker, } \\
\text { no HT }\end{array}$ \\
\hline & Binary & $\begin{array}{l}\text { HT without beta-blocker } \\
\text { versus no beta-blocker, no HT }\end{array}$ \\
\hline & Binary & $\begin{array}{c}\text { Beta-blocker for HT versus } \\
\text { no beta-blocker, no HT }\end{array}$ \\
\hline $\begin{array}{l}\text { Physician efficiency index } \\
(/ 1000)\end{array}$ & Continuous & $\begin{array}{l}\text { See Data and Methods } \\
\text { section for detail }\end{array}$ \\
\hline Medicare & Binary & Yes versus no \\
\hline Workers' compensation & Binary & Yes versus no \\
\hline Commercially insured & Binary & Yes versus no \\
\hline
\end{tabular}

CT Computed tomography; ED Emergency department; HT Hypertension; Lab Laboratory; LBP Low back pain; Med Medical; MRI Magnetic resonance imaging; PCP Primary care physician

$\mathrm{PEI}_{\mathrm{ij}}$ represents the PEI of patient $i$ who was treated by provider $j$ during a calendar year. $\mathrm{N}$ represents the total number of patients (including patient $i$ ) treated by provider $j$ during the same calendar year. Therefore, the PEI captures the average per-year cost of care across all patients treated by provider $j$, except for patient $i$, during the given calendar year.

\section{RESULTS}

Figure 2 illustrates the result of applying the predictive model and selected cut-points to the data. Specifically, the following steps were used:

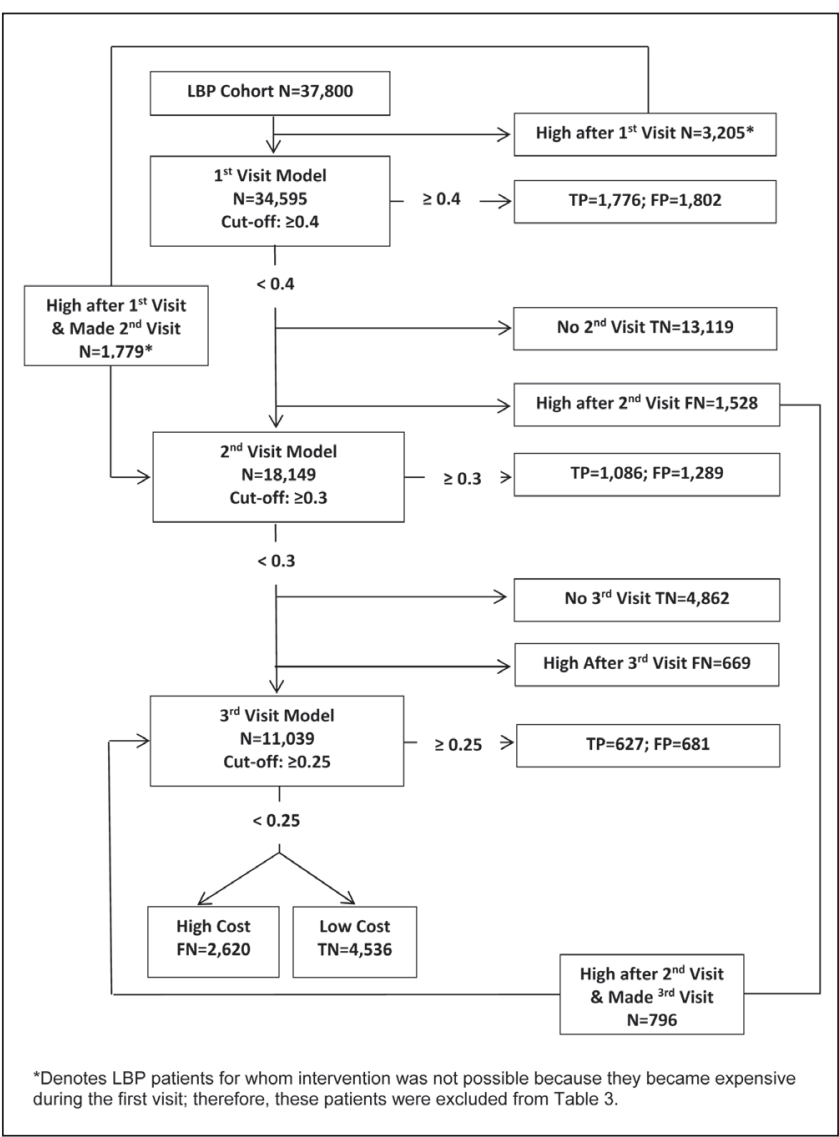

Figure 2) Predictive modelling flow diagram. FN False negative; FP False positive; LBP Low back pain; TN True negative; TP True positive

Step 1: Exclude 3205 patients from the model who are high cost at the end of the first visit

These cases were ignored only for the first visit because it was assumed there is nothing that could have been done about them in advance of the first visit.

Step 2: Complete the logistic model using data on the 34,595 patients who completed the first visit

That model yielded a c-statistic of 0.683 (see Appendix for the complete regression output). A diversity of covariates was statistically significant including smoking status, depression diagnosis and the physician index.

Step 3: Based on step 2, calculate the probability that each patient in the sample will become expensive at some point in the future during the one-year period

Using cut-points for the patient probability of being high cost $>0.4$ AND actual cost $>70$ th percentile, 1776 true positives and 1802 false positives were identified. These patients were removed from consideration in the second visit model because it was assumed that there would be an intervention for these patients.

Step 4: Identify patients who did not complete a second visit and were not expensive by the end of the first visit and made no subsequent visits

These patients $(n=13,119)$ were categorized as true negatives because they were all low-cost patients for whom a decision not to intervene was made by default because they simply do not have a second visit; patients who had a second visit but who ended up being high cost at the end of the second visit $(n=1528)$ were removed. These patients were defined as false negatives because they were not detected before they became high cost. 


\begin{tabular}{|c|c|c|c|}
\hline \multirow[b]{2}{*}{ Screening status } & \multicolumn{2}{|c|}{ True status } & \multirow[b]{2}{*}{ Total } \\
\hline & Low cost & High cost & \\
\hline \multirow[t]{3}{*}{ Low cost } & $13,119^{*}$ & $1528^{*}$ & 27,334 \\
\hline & $4862^{\dagger}$ & $669^{\dagger}$ & \\
\hline & $4536^{\ddagger}$ & $2620^{\ddagger}$ & \\
\hline \multirow[t]{3}{*}{ High cost } & $1802^{*}$ & $1776^{*}$ & 7261 \\
\hline & $1289^{\dagger}$ & $1086^{\dagger}$ & \\
\hline & $681^{\ddagger}$ & $627^{\ddagger}$ & \\
\hline Total & 26,289 & 8306 & 34,595 \\
\hline
\end{tabular}

Sensitivity $=42.0 \%$; Specificity $=85.7 \%$; positive predictive value $=48.1 \%$. *Obtained from first visit; †Obtained from second visit; $¥$ Obtained from third visit

Step 5: Include previously excluded patients into subsequent visit models

Among the 3205 patients who were excluded in the first visit model because they were expensive after the first visit (as described in step 1), 1779 patients $(55.5 \%)$ were brought back into the sample for the second visit model because they made the second visit. Similarly, of the 1528 patients who were excluded in the second visit model because they were expensive after the second visit, 796 (52\%) were brought back into the sample for the third visit model because they made a third visit.

Step 6: Run a logistic model for the second and third visit, respectively, and repeat steps 2 through 4 again corresponding to each visit

The c-statistic from the second visit model was 0.795 . For the second visit model, a probability cut-point of 0.3 was used. Again, these patients were removed from consideration in the third visit model because it was assumed that there would be an intervention for these patients. The third visit model had a c-statistic of 0.741 . The probability cut-point for the third visit model was 0.25 .

See the Appendix for the complete logistic regression model outputs. Note that in second and third visit models, as the number of patients included in each model decreases, some covariates show little to no variation (eg, the number of patients for whom computed tomography was ordered was close to zero in second and third visits). Such covariates were, therefore, excluded from these models.

Table 4 suggests that the overall sensitivity of the model was $42 \%$, the specificity was $86 \%$ and the positive predictive value was $48 \%$.

\section{DISCUSSION}

In the present study, we explored the feasibility of using EHR to potentially develop a dynamic predictive model that identifies patients who are likely to become expensive within the first year since their first LBP encounter with a health care provider. Several interesting patterns emerge in terms of significance of some of the predictors, as shown by the logistic regression model estimates in the Appendix: women are less likely to become expensive than men; however, patients who had workers' compensation as their primary payer type, had higher use of prescription opioid drugs or were smokers before the first LBP visit are more likely to become expensive. Furthermore, a higher PEI score is a consistent predictor of higher probability of becoming expensive, and patients whose first LBP encounter was with a PCP are less likely to become expensive than those who received their first LBP care elsewhere. This indicates that individual physicians' practice patterns may be a significant determinant of whether a patient will incur high LBP-related cost of care. These findings also suggest that there may be a handful of potentially useful signals present in a patient's longitudinal medical record.
The three logistic regression models corresponding to the first, second and third visit models had c-statistics of $0.683,0.795$ and 0.741 , respectively, which is certainly within an acceptable range according to Hosmer and Lemeshow and comparable with the Framingham Heart Study risk calculator, which is 0.77 (12). Our approach of using a dynamic model to inform decisions on how to manage patients dependent on whether they are at their first, second or third LBP visit with the provider also generated an overall sensitivity of $42 \%$, specificity of $86 \%$ and the positive predictive value was $48 \%$. This is comparable with other tools for addressing $\operatorname{LBP}(13,14)$.

This finding is subject to several potential limitations. First, our patient cohort was limited to those who had at least one year of followup after the first LBP visit. This may have biased the sample selection process because patients who did not meet this criterion may have had systematically less severe LBP, for instance. We argue, however, that such patients were beyond the intended scope of the present study because they were, by definition, outside the care providers' control and cannot be effectively managed. Second, during and since the study period (2007 to 2011), Geisinger Health System has been expanding and redesigning its primary care clinics, most notably via the implementation of its patient-centred medical homes, which aim to increase access to primary care and prevent exacerbations that lead to more expensive care in general (15). However, because patient-centred medical homes do not explicitly target LBP patients or LBP-related care per se, their implication on the present study is unclear.

Our approach is unique in that it relies on data elements that can be readily obtained from standard electronic medical records rather than on health insurance claims data, which typically entail a significant delay between the time of patient encounter and the time the data actually become available for analysis. Thus, the timeliness of our EHR-based predictive modelling approach allows the potential to identify expensive patients in real time before they actually become truly expensive. For instance, our predictive model can be implemented in PCP office settings and incorporated into the routine care modules for managing LBP patients, allowing physicians an additional tool to proactively identify expensive patients at the point of care and to provide appropriate care management plans during the encounter for such patients.

In reality, however, there are several obstacles to implementing our model in such a way. First, not all the predictors included in the present study may be readily available in a typical EHR database, especially the financial and economic variables. One such variable is PEI, which, in the present study, relied on using the claims-based cost imputation method as described in the Method section and in the Appendix. However, we note that even PEI can potentially be calculated quickly based on quasi-price information that is often available in EHR, such as the charge data. What matters in this context is that the available data capture the relative intensity of resource use at the patient level, not the absolute dollar amounts.

Second, the model assumes a comprehensive and mature EHR database containing longitudinal records of every patient covering at least several months of encounter data before the first LBP encounter. This assumption is unlikely to be true in many - if not most - of the health care delivery systems in the United States and even beyond. In a fragmented health care delivery system - such as those typically found in the United States - creating such an extensive database requires integration of discrete data elements across different stakeholders (ie, both providers and payers) and settings (ie, both outpatient and inpatient) at different time periods for each individual patient - a daunting task that poses significant technical as well as legal challenges. Currently, only a handful of large integrated health care delivery systems in the United States (including Geisinger) offers such data capabilities. As the era of electronic medical records move beyond its current infancy, however, EHR-based predictive modelling strategies, such as the one presented herein, are likely to become more feasible and commonplace; consequently, such obstacles are likely to become less of a barrier and challenge in the future. 
DISCLOSURES: This study was sponsored by Pfizer Inc, New York, New York. Geisinger Health System was paid by Pfizer Inc in connection with the development of the manuscript. DM, XY and JAB are employees of Geisinger Health System. WFS was an employee of Geisinger Health System at the time the study was conducted and was a paid in connection with the development of this manuscript. MVK and WFS were paid consultants to Pfizer Inc in connection with this study and the development of the manuscript. JH and JM are employees of Pfizer Inc.

AUTHOR CONTRIBUTIONS: Conception and design: WFS, DDM, $\mathrm{XY}, \mathrm{JAB}, \mathrm{JH}$ and $\mathrm{MRV}$; acquisition of data: $\mathrm{XY}$ and $\mathrm{JH}$; analysis and interpretation: WFS, DDM, XY, JAB, JM, JH and MRV; drafting the manuscript: WFS, DDM, XY, JAB and JH; critical revision: DDM, XY, JM, JH and MRV.

Cost imputation algorithm

\section{APPENDIX}

As is typically the case, Geisinger's EHR data lack cost information. To circumvent this problem, we developed a regression-based cost imputation method based on Geisinger Health Plan (GHP) claims data as outlined below:

1. Start by applying the same inclusion and exclusion criteria to the claims data as done for the EHR data to select the eligible patient population from the claims data;

2. Categorize all encounter types in EHR and claims into a set of mutually exclusive major categories. In this study, we use the following major categories: inpatient visit, outpatient visit, emergency department (ED), diagnostic imaging (ie, $\mathrm{x}$-rays, computed tomography and magnetic resonance imaging), and all prescription drugs. Professional charges, which are typically available as separate claim types, are assumed to have been incurred in every encounter in EHR;

3. In the claims data, estimate the following multivariate regression model using a Generalized Linear Model with log link and gamma distribution function:

$$
\begin{aligned}
\text { Mean Cost }=\beta_{0}+\beta_{1}(\text { Encounter Type })+\beta_{2}(\text { Medicare }) \\
+\beta_{3}(\text { Age })+\beta_{4}(\text { Gender })
\end{aligned}
$$

'Encounter Type' denotes a set of binary indicator variables that represents each major encounter type category (eg, inpatient, outpatient, ED, etc.); 'Medicare' is a binary indicator variable that equals 1 if the patient has Medicare coverage and 0 otherwise; 'Age' is a continuous variable capturing the patient's age at the time of the study; and "Sex" captures the patient's ex

1. Take the beta coefficient estimates obtained in 3) and apply them to similarly structured EHR data to obtain the estimated mean cost in the EHR.

The above method can be modified by introducing interaction effects between the encounter type variables and age or sex, for instance. In our estimates, the results were not sensitive to such alternative specifications. The resulting cost estimates can be interpreted as 'imputed cost' under the hypothetical scenario that the patient had been covered by GHP. The advantage of this cost imputation method is that it is not necessary that those patients who are included in the claims data be also included in the EHR data; as long as the structure of the EHR data can be modified to accommodate the above regression model, estimated cost can be obtained for that patient. The disadvantage of this method is that its accuracy may depend on the potentially subjective categorization of claim and encounter types.

\section{Complete logistic regression results according to visit}

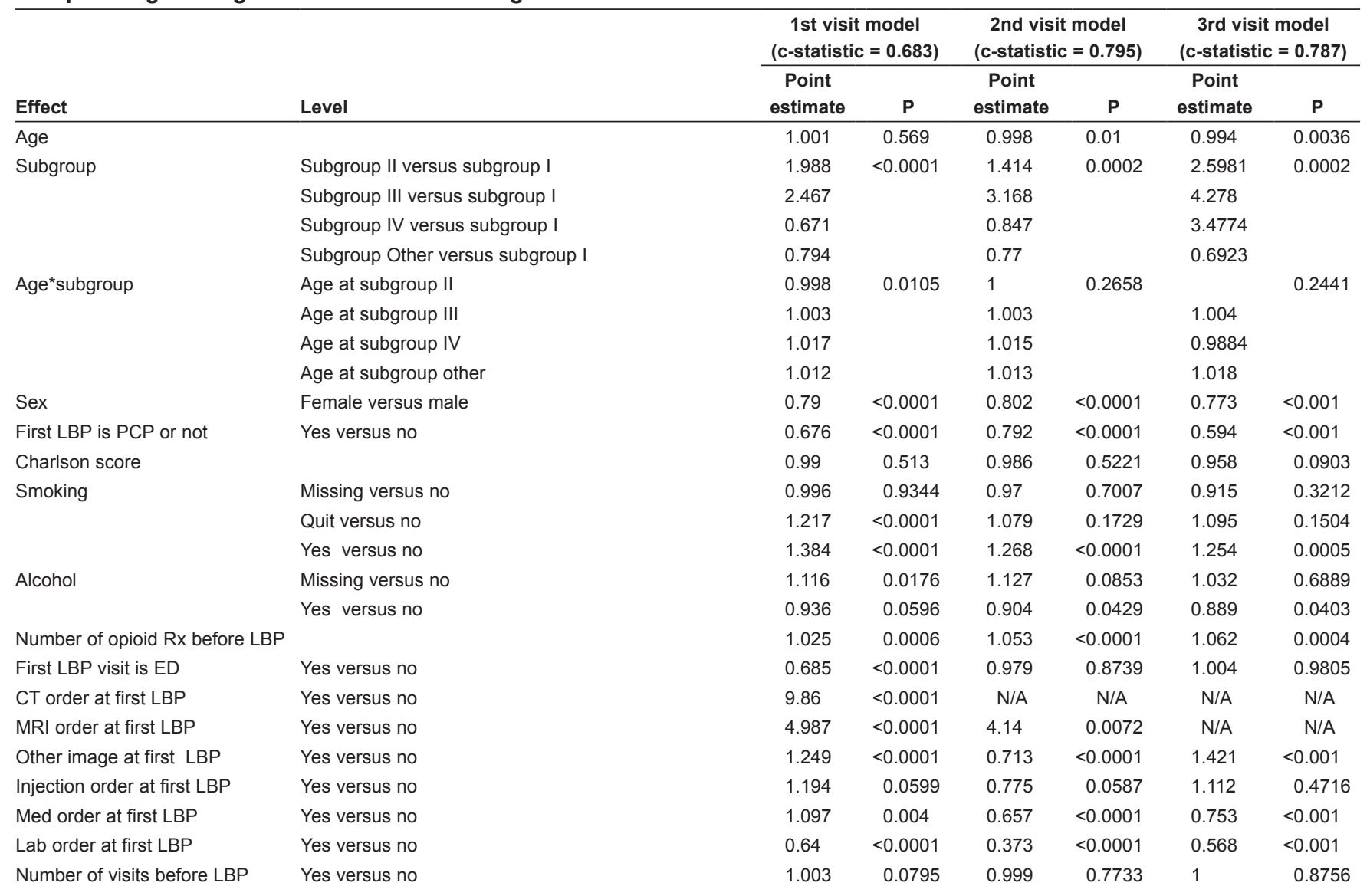




\begin{tabular}{|c|c|c|c|c|c|c|c|}
\hline \multirow[b]{2}{*}{ Effect } & \multirow[b]{2}{*}{ Level } & \multicolumn{2}{|c|}{$\begin{array}{c}\text { 1st visit model } \\
\text { (c-statistic }=0.683\end{array}$} & \multicolumn{2}{|c|}{$\begin{array}{c}\text { 2nd visit model } \\
\text { (c-statistic }=0.795)\end{array}$} & \multicolumn{2}{|c|}{$\begin{array}{c}\text { 3rd visit model } \\
\text { (c-statistic }=0.787 \text { ) }\end{array}$} \\
\hline & & $\begin{array}{c}\text { Point } \\
\text { estimate }\end{array}$ & $\mathbf{P}$ & $\begin{array}{c}\text { Point } \\
\text { estimate }\end{array}$ & $\mathbf{P}$ & $\begin{array}{c}\text { Point } \\
\text { estimate }\end{array}$ & $\mathbf{P}$ \\
\hline Fibromyalgia & Yes versus no & 1.129 & 0.0284 & 1.184 & 0.0334 & 1.264 & 0.0091 \\
\hline \multirow[t]{4}{*}{ Depression } & Level 2 versus level 1 & 1.373 & $<0.0001$ & 1.403 & $<0.0001$ & 1.405 & $<0.001$ \\
\hline & Level 3 versus level 1 & 1.164 & 0.756 & 0.742 & 0.6488 & 1.661 & 0.5002 \\
\hline & Level 4 versus level 1 & 1.343 & $<0.0001$ & 1.285 & 0.0003 & 1.076 & 0.3657 \\
\hline & Level 5 versus level 1 & 1.61 & $<0.0001$ & 1.491 & $<0.0001$ & 1.269 & 0.0009 \\
\hline Allergic rhinitis & Yes versus no & 0.897 & 0.007 & 0.842 & 0.0023 & 0.867 & 0.0237 \\
\hline Gastroesophageal reflux disease & Yes versus no & 0.952 & 0.185 & 0.939 & 0.2287 & 0.882 & 0.0312 \\
\hline Arthritis & Yes versus no & 1.078 & 0.0504 & 1.136 & 0.022 & 1.27 & 0.0002 \\
\hline \multirow[t]{3}{*}{ Beta-blocker and HT } & $\begin{array}{l}\text { Beta-blocker order not for HT versus no beta-blocker, } \\
\text { no HT }\end{array}$ & 1.003 & 0.97 & 0.942 & 0.5883 & 1.036 & 0.7728 \\
\hline & HT without beta-blocker versus no beta-blocker, no HT & 0.964 & 0.342 & 0.947 & 0.3351 & 0.831 & 0.0032 \\
\hline & Beta-blocker for HT versus no beta-blocker, no HT & 0.962 & 0.4662 & 0.892 & 0.1256 & 0.892 & 0.1687 \\
\hline Physician efficiency index (/1000) & & 1.08 & $<0.0001$ & 1.048 & 0.0048 & 1.21 & $<0.001$ \\
\hline Time interval (month) & & $\mathrm{N} / \mathrm{A}$ & N/A & 0.811 & $<0.0001$ & 0.9 & $<0.001$ \\
\hline Medicare & Yes versus No & 1.047 & 0.3164 & 0.999 & 0.9854 & 1.006 & 0.9377 \\
\hline Workers' Compensation & Yes versus No & 1.883 & $<0.0001$ & 1.481 & 0.0479 & 5.48 & $<0.001$ \\
\hline Commercial insured & Yes versus No & 0.88 & 0.0001 & 0.923 & 0.0887 & 1.005 & 0.9236 \\
\hline
\end{tabular}

CT Computed tomography; ED Emergency department; HT Hypertension; Lab Laboratory; LBP Low back pain; Med Medical; MRI Magnetic resonance imaging; PCP Primary care physician; Rx Prescriptions

\section{REFERENCES}

1. Deyo RA, Mirsa SK, Martin BI. Back pain prevalence and visit rates: Estimates from the US national surveys, 2002. Spine 2006;31:2724-7.

2. Ricci JA, Stewart WF, Chee E, Leotta C, Foley K, Hochberg MC. Back pain exacerbations and lost productive time costs in United States workers. Spine 2006;31:3052-60.

3. Cypress BK. Characteristics of physician visits for back symptoms: A national perspective. Am J Public Health 1983;73:389-95.

4. Andersson GB. Epidemiological features of chronic low-back pain. Lancet 1999;354:581-5.

5. Von Korff M, Saunders K. The course of back pain in primary care. Spine 1996;21:2833-7.

6. Atlas SJ, Deyo RA. Evaluating and managing acute low back pain in the primary care setting. J Gen Intern Med 2001;16:120-31.

7. Martin BI, Deyo RA, Mirza SK, et al. Expenditures and health status among adults with back and neck problems. JAMA 2008;299:656-64.

8. Foster NE. Barriers and progress in the treatment of low back pain. BMC Med 2011;9:108

9. Cherkin DC, Deyo RA, Loeser JD, Bush T, Waddell G. An international comparison of back surgery rates. Spine 1994;19:1201-6.
10. Chou R, Qaseem A, Snow V, et al; Clinical Efficacy Assessment Subcommittee of the American College of Physicians; American College of Physicians; American Pain Society Low Back Pain Guidelines Panel. Diagnosis and treatment of low back pain: A joint clinical practice guideline from the American College of Physicians and the American Pain Society. Ann Intern Med 2007;147:478-91

11. Vogt MT, Kwoh CK, Cope DK, Osial TA, Culyba M, Starz TW. Analgesic usage for low back pain: Impact on health care costs and service use. Spine 2005;30:1075-81.

12. Wilson PW, D'Agostino RB, Levy D, Belanger AM, Silbershatz H, Kannel WB. Prediction of coronary heart disease using risk factor categories. Circulation 1998;97:1837-47.

13. Dionne CE, Bourbonnais R, Frémont P, Rossignol M, Stock SR, Larocque I. A clinical return-to-work rule for patients with back pain. CMAJ 2005;172:1559-67.

14. Weir S, Aweh G, Clark RE. Case selection for a Medicaid chronic care management program. Health Care Financ Rev 2008;30:61-74.

15. Gilfillan RJ, Tomcavage J, Rosenthal MB, et al. Value and the medical home: Effects of transformed primary care. Am J Manag Care 2010;16:607-14. 


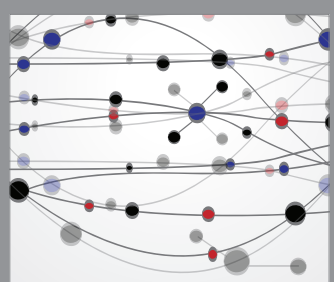

The Scientific World Journal
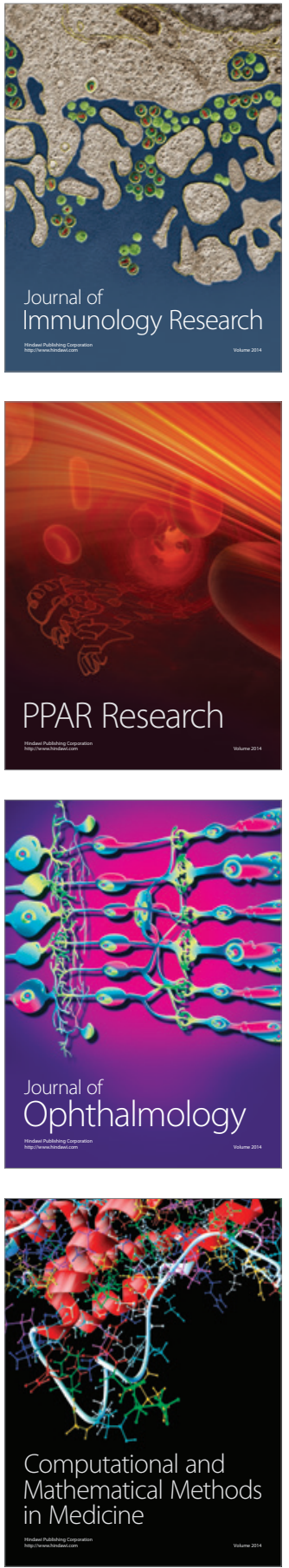

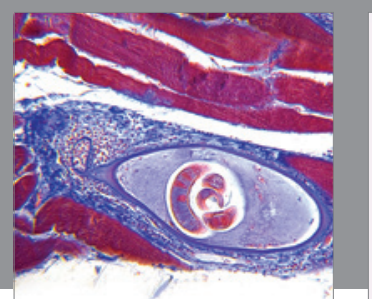

Gastroenterology Research and Practice

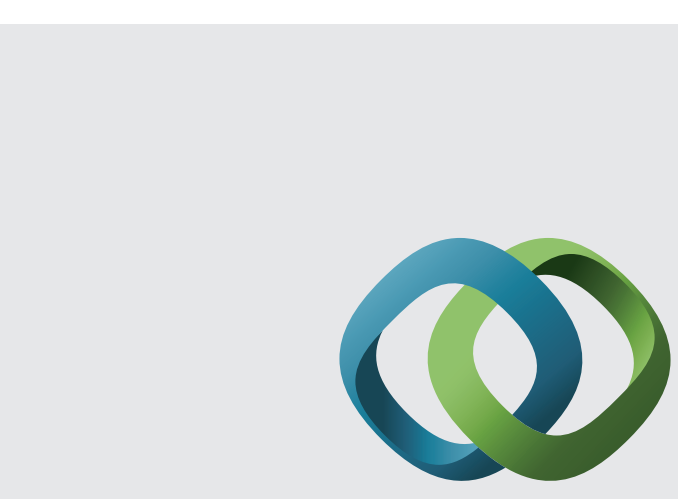

\section{Hindawi}

Submit your manuscripts at

http://www.hindawi.com
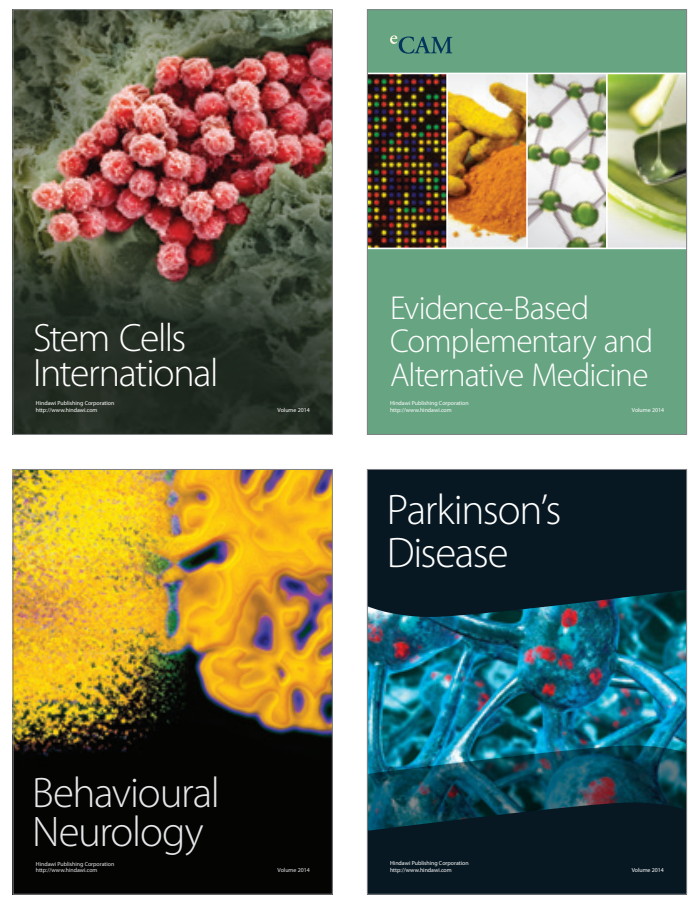
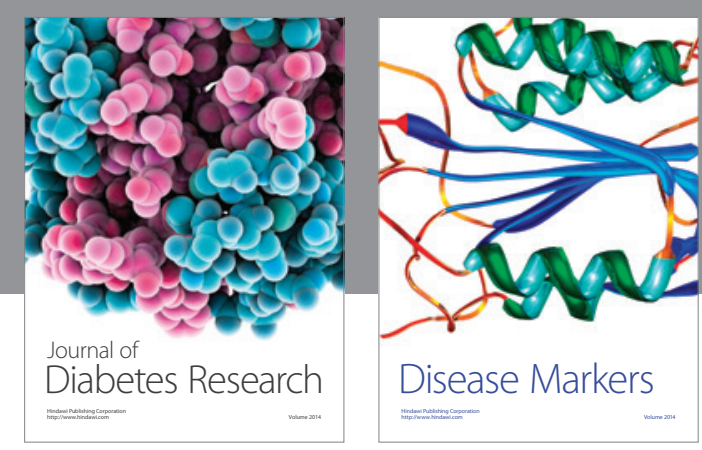

Disease Markers
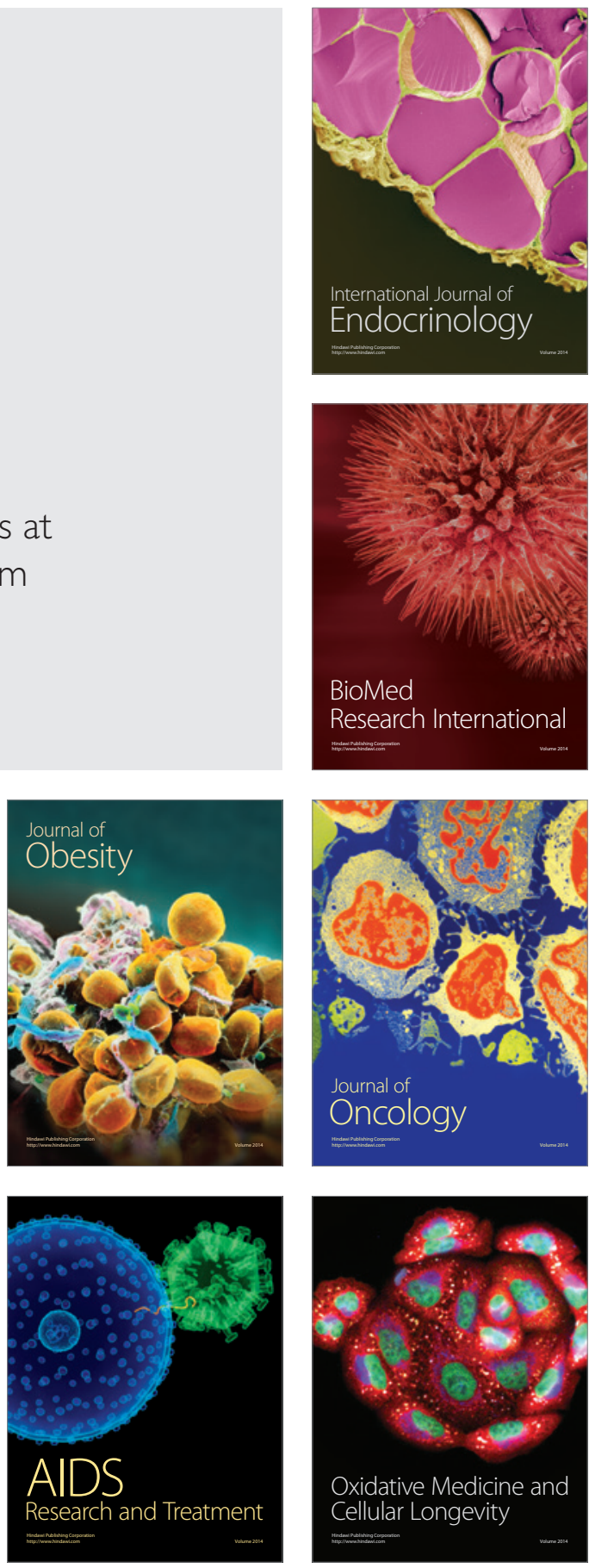